\title{
Direitos humanos e violência contra as mulheres: uma luta contra a sociedade patriarcal-racista-capitalista
}

\author{
Human rights and violence against women: as struggle against the patriarchal-racist- \\ capitalist society
}

Mirla Cisne*

\begin{abstract}
Resumo:
O objetivo deste artigo é problematizar a importância da luta por direitos humanos no combate às violências contra as mulheres, inserindo essa luta nos limites e contradições de uma sociedade que tem a desigualdade e a exploração de classe, raça/etnia e sexo como elementos constituintes. Nesse entendimento, as múltiplas formas de violência contra a mulher, seja ela física, seja psicológica, seja sexual, seja obstétrica, seja patrimonial, seja social não resultam das relações individuais isoladamente, mas, sobretudo, são estruturadas pelas relações sociais de sexo, classe, raça/etnia que consubstanciam a sociedade patriarcal-racista-capitalista. São essas relações sociais que dão base à ideologia, naturalizando situações de violências às mulheres. É essa sociedade permeada por relações de opressão, exploração e também apropriação sobre as mulheres que promove cotidianamente situações de violência permeadas e potencializadas pela desigualdade de classe, pelo sexismo e pelo racismo, o que não apenas provoca a demanda pela luta por direitos humanos, mas a exige. Falar em direitos humanos para as mulheres é falar na necessidade de lutar por uma sociedade sem violência e sem as apropriações, explorações e opressões que dão corpo às múltiplas violências contra as mulheres.
\end{abstract}

Palavras-chave: Direitos humanos; Violência contra as mulheres; Patriarcado; Racismo.

\begin{abstract}
:
The purpose of this article is to discuss the importance of the struggle for human rights in fighting against women violence by entering this fight within the limits and contradictions of a society that hasine quality and class exploitation, race/ethnicity and gender as constituent elements. In this understanding, the multiple form sof violence against women, whe ther physical, psychological, sexual, obstetric, equityor social, not the result of individual relationships alone, but above all are structured by social relation sof gender, class, race/ethnicity that embody the patriarchal-racistcapitalist society. It is these social relations that under lie the ideology that naturalizes situation sof violence to women. It is this society permeated by relations of oppression, exploitation and also appropriation of women who daily promotes situation sof violence permeated and potentiated by class inequality, sexismandracism, whichnot only causes the demand for fighting for human rights, but the demands. Speaking of human rights for women is talking about the need to fight for a society without violence and without the appropriation, exploitation and oppression that embody the multiple violence against women.
\end{abstract}

\footnotetext{
* Universidade Estadual do Rio Grande do Norte. Doutora em Serviço Social pela Universidade do Estado do Rio de Janeiro, Professora da Universidade do Estado do Rio Grande do Norte (UERN), E-mail: mirlacisne@gmail.com
} 
Key words: Human rights; Violence against women; Patriarchy; Racism.

\title{
Introdução
}

A reivindicação das mulheres por direitos humanos não é recente e resulta da necessidade de buscar dignidade, contrapondo-se a um sistema patriarcal que as nega e as violenta cotidianamente. A Declaração dos direitos da mulher e da cidadã é um marco histórico na luta por direitos humanos femininos, escrita por Olympe de Gouges1, em 1791, dois anos após a Revolução Francesa. Na Conclusão da declaração, Olympe de Gouges (2007, p.4) escreve:

\begin{abstract}
Mulher, acorda! A força da razão faz-se ouvir em todo o universo: reconhece teus direitos. O poderoso império da natureza já não está limitado por preconceitos, superstição e mentiras. A bandeira da verdade dissipou todas as nuvens da parvoíce da usurpação. O homem escravo multiplicou suas forças, precisou recorrer às tuas (forças) para romper seus grilhões. Tornado livre, ele fez-se injusto em relação à sua companheira. Mulheres! Mulheres, quando deixareis de ser cegas? Quais são as vantagens que obtivestes na Revolução? Um menosprezo mais marcado, um desdém mais perceptível.
\end{abstract}

Esse chamado de Gouges não foi por acaso. Havia e, em grande medida, podemos dizer que, ainda, há relações materiais concretas sem que direitos e privilégios dos homens sejam assegurados em detrimento das mulheres. Privilégios constituídos pelo sistema patriarcal que, por sua vez, é alicerçado por relações de violências, opressões e explorações sobre as mulheres.

Um dos artigos que merece destaque na declaração de Gouges é o décimo terceiro, no qual afirma:

Para a manutenção da força pública, e para os gastos administrativos, as contribuições da mulher e do homem devem ser iguais; ela participa de todos os trabalhos ingratos, de todas as tarefas pesadas; ela deve, por conseguinte, ter a mesma participação da distribuição dos postos, dos empregos, dos cargos, das dignidades e da indústria (GOUGES, 2007, p.4).

\footnotetext{
${ }^{1}$ Marie Gouze, conhecida como Olympe de Gouges (como assinava suas peças de teatro e panfletos), ainda que com limites marcados pelo seu tempo histórico, foi uma revolucionária. Nasceu em 1748 e morreu guilhotinada em 1793. Sofreu essa condenação por ter sido considerada opositora aos revolucionários Robespierre e Marat (líderes da Revolução Francesa). Esses “a consideraram mulher 'desnaturada' e 'perigosa demais'". Ao se dirigir à guilhotina, ela afirmou, referenciando o artigo dez de sua declaração dos direitos da mulher e da cidadã: "A mulher tem o direito de subir ao cadafalso; ela deve ter igualmente o direito de subir à tribuna” (GOUGES, 2007, p.1).
} 
Esse artigo proposto por Gouges faz-se absolutamente atual ao denunciar a persistência do patriarca do pós-revolução francesa, marco referencial e modelar do sistema capitalista. O patriarcado aqui se expressa em um dos seus pilares estruturantes: a divisão sexual do trabalho, que se revela não apenas na diferenciação entre trabalhos considerando feminismos e masculinos, mas, também, na hierarquia e na desigualdade no acesso aos meios de produção, ao trabalho e à riqueza por ele produzida. Com isso, postos de trabalho considerados masculinos são mais valorizados e melhor remunerados, enquanto os considerados femininos são desvalorizados e alguns sequer considerados trabalho, como é o caso do doméstico.

É preciso perceber que a reivindicação por direitos humanos para as mulheres, defendida por Gouges, está limitada aos marcos históricos da Revolução Francesa e de seus ideais. Todavia, Gouges explicita e questiona as contradições de uma revolução que proclama "igualdade, fraternidade e liberdade" e não assegurava isso concretamente para a classe trabalhadora, especialmente, para as mulheres que ainda pesava sobre si a desigualdade dentro de uma mesma classe e uma exploração de sua força de trabalho de forma mais intensa, precária e desvalorizada. O novo sistema em ascensão, portanto, não apontava para a superação do patriarcado feudal, mas, ao contrário, o manteve funcionalmente para o seu desenvolvimento, ainda que sob novas determinações sócio históricas. Assim, os privilégios masculinos ainda permaneceram em detrimento da liberdade e da autonomia das mulheres.

É diante desse sistema de desigualdade entre os sexos que a luta das mulheres por direitos humanos se inscreve. Apesar de reivindicados formalmente por Olympe de Gouges desde 1791, foi apenas por meio da Declaração e o Programa de Viena, em 1993, que os direitos das mulheres, no campo internacional, passaram a ser considerados direitos humanos universais. Essa morosidade não é algo espontâneo, tampouco natural, mas revelador da necessidade burguesa em manter o patriarcado, já que esse é funcionalmente útil para sua lógica de produção e reprodução2.

Anterior a esse reconhecimento internacional, resultante de lutas históricas do feminismo pelo combate à violência contra a mulher, já havia mecanismos de proteção aos direitos das mulheres, com destaque especial para a Convenção sobre a Eliminação de

\footnotetext{
${ }^{2}$ Sobre a relação entre patriarcado e capitalismo, conferir Cisne (2014).
} 
todas as Formas de Discriminação contra a Mulher (1984) e da Convenção para Prevenir, Punir e Erradicar a Violência contra a Mulher (1995), Convenção de Belém do Pará.

Não se pode negar a importância desses mecanismos voltados para o combate à violência, até porque, em grande medida, resultam da luta legítima das mulheres. É preciso, no entanto, problematizar o terreno sócio histórico e econômico em que esses direitos são demandados ou mesmo formalmente legalizados, no caso, uma sociedade capitalistapatriarcal-racista.

Portanto, o objetivo deste texto é problematizar a importância da luta por direitos humanos no combate às violências contra as mulheres, compreendendo esses direitos não como um fim em si mesmo, mas inseridos nos limites e contradições de uma sociedade que tem a desigualdade e a exploração de classe, raça/etnia e sexo como elementos constituintes.

\section{Direitos humanos: contradições, limites e importância}

Parto da compreensão histórica da importância indiscutível da defesa dos direitos humanos diante de uma sociedade medularmente desumana, ao ser permeada por opressões e explorações de classe, raça/etnia e sexo/gênero. Todavia, não considero os direitos humanos como uma estratégia, ou melhor, um objetivo-fim, posto que a própria luta por sua concretização revela a persistência de uma sociedade desigual e que fere cotidianamente a dignidade e os direitos humanos. Assim, o que se necessita é uma sociedade em que não seja necessário clamar por direitos humanos, mas que eles já estejam naturalmente presentes nas relações sociais. A estratégia que defendo, portanto, centra-se na construção de um novo projeto societário que, obviamente, não é incompatível com a luta por direitos humanos, ao contrário, essa luta é uma tática fundamental, até porque permite, entre outros ganhos políticos e civilizatórios, explicitar as contradições do atual sistema.

O debate sobre os direitos humanos tem os seus primeiros contornos com as lutas da burguesia revolucionária, baseados no iluminismo e no liberalismo, contra o despotismo dos Estados Absolutistas. Nesse primeiro momento, eles são formalizados como direitos civis e políticos, ou direitos individuais. Aqui, não se pode esquecer os limites, sumariamente apontados na introdução deste artigo e denunciadas por Gouges da 
Revolução Francesa. Os direitos humanos foram, portanto, historicamente permeados por contradições nos marcos do capitalismo.

Vinculados à luta pela dignidade, os direitos humanos constroem um arcabouço jurídico e político em torno da Declaração Universal dos Direitos Humanos, de 1948, que define em seus artigos 10 e 2 은

\section{Art. 1}

Todos os seres humanos nascem livres e iguais em dignidade e direitos. São dotados de razão e consciência e devem agir em relação uns aos outros com espírito de fraternidade.

Art 2

1.Todo ser humano tem capacidade para gozar os direitos e as liberdades estabelecidos nesta Declaração, sem distinção de qualquer espécie, seja de raça, cor, sexo, idioma, religião, opinião política ou de outra natureza, origem nacional ou social, riqueza, nascimento, ou qualquer outra condição (NAÇÕES UNIDAS, 1998, destaques nossos).

A afirmação da necessidade de garantia da dignidade abre a perspectiva de entender os direitos humanos não apenas como os direitos civis e políticos, mas, também, sociais, econômicos, sexuais, reprodutivos, culturais e ambientais. A questão a se problematizar é como assegurar esses direitos em uma sociedade patriarcal, racista e classista, medularmente desigual? Por exemplo, como descrito acima, no Artigo 10 da Declaração Universal dos Direitos Humanos, afirma-se: "Todos os seres humanos nascem livres e iguais em dignidade e direitos", pergunto: isso é possível em uma sociedade em que a propriedade privada impede que os seres humanos nasçam em iguais condições socioeconômicas? Da mesma forma, questiono como assegurar a não distinção de cor e sexo em uma sociedade patriarcal e racista?

Em outras palavras, o que quero dizer é que assegurar direitos do ponto de vista normativo é importante, mas insuficiente. A luta para dar materialidade aos direitos humanos é um desafio para expor as contradições dessa sociedade e ir além dos discursos ideológicos que, muitas vezes, os direitos humanos são inscritos. Nesse sentido, não basta afirmar normativamente a não discriminação e a igualdade, é preciso construir uma sociedade igualitária, antirracista e antipatriarcal.

Se, por um lado, os direitos humanos revelam limites, por outro, também resultam de avanços e conquistas advindas de lutas legítimas, como bem elucida Silvana Santos (2010, p.30): 
Os direitos humanos (DH) possuem uma trajetória histórica complexa e permeada por contradições, que tanto revelam sua utilização como instrumento de dominação ideológica da burguesia, como também se constituem, por meio de determinadas lutas, possibilidades de resistência às formas de exploração e de opressão típicas da sociedade capitalista.

Nesse sentido, apesar de também ser utilizado como um instrumento ideológico para legitimação do capitalismo, os direitos humanos ganham notável relevância ao denunciarem historicamente situações de barbáries, explorações e opressões que negam a igualdade substantiva, a liberdade e a diversidade humana.

No Brasil, em uma conjuntura progressivamente conservadora e reacionária, com nítidas marcas de uma formação racista e patriarcal, a luta pelos direitos não é apenas importante, é indispensável para se defender a dignidade humana de grupos social e historicamente discriminados como as mulheres, destacadamente as negras e indígenas.

A superação do que estrutura cotidianamente a negação dos direitos humanos, ou seja, o sistema patriarcal-racista-capitalista demanda associar a luta por direitos a "uma nova forma de organizar as relações sociais, fundada no trabalho associado e na socialização da riqueza material e espiritual produzida" (SANTOS, 2010, p.35). Essa concepção se faz importante na medida em que se compreende a necessidade de eliminar a raiz das desigualdades sociais: a contradição entre capital $x$ trabalho.

Compartilho, portanto, do pensamento de que enquanto houver exploração de classe haverá desigualdades que, por sua vez, impedem a concretização plena dos direitos humanos. É também indispensável compreender que as desigualdades, molas propulsoras da negação dos direitos, não são permeadas apenas pelas relações de classe, mas, também, pelas relações sociais de sexo e de raça/etnia. Dito de outra maneira, é importante compreender que as classes não são homogêneas, mas atravessadas ou mesmo constituídas pelas relações sociais de sexo, raça/etnia (CISNE, 2014).

Assim, a luta por diretos humanos se associada a um projeto societário antirracista, antipatriarcal, voltado para a eliminação das classes sociais, fortalece a perspectiva da emancipação não apenas política, mas humana e radicalmente democrática.

\section{Direitos humanos para as mulheres: para além da exploração e da apropriação}

Os direitos humanos relativos às mulheres merecem uma especial atenção. No capitalismo, todas as pessoas não privilegiadas do ponto de vista da classe social, 
demandam direitos humanos, já que nesse sistema é ineliminável a exploração e, por conseguinte, as injustiças, desigualdades e opressões. Todavia, às mulheres há uma outra dimensão da desigualdade: o patriarcado. O patriarcado, aqui entendido como um sistema de opressão, apropriação e exploração sobre as mulheres, fora fundido com o capitalismo e o racismo. Como sistema, ele se faz presente em todas as relações sociais, inclusive nas relações entre uma mesma classe. Dito de uma maneira diferente, é possível afirmar que todas as pessoas não pertencentes às classes dominantes têm direitos violados, mas, às mulheres, além da exploração/opressão de classe que também afeta aos homens trabalhadores, pesa também as relações de sexagem, termo elaborado por Guillaumin, entendido como um prolongamento dos conceitos de escravidão e servidão ${ }^{3}$ (FALQUET, 2012). Por meio da sexagem, as mulheres são apropriadas não apenas no que diz respeito a sua força de trabalho, mas, também, ao seu corpo e a sua vida. A sexagem denota a apropriação material concreta da individualidade corporal das mulheres, em um processo que as tira da condição de sujeito e as tornam "coisas" (GUILLAUMIN, 2005).

Nicole Claude Mathieu (2005, p.160) ressalta que a sexagem designa a "relação social de classe que se revela na apropriação do corpo, do trabalho e do tempo do conjunto das mulheres para o benefício pessoal e social dos homens em seu conjunto". Decorrente da sexagem, a apropriação das mulheres se diferencia ou vai para além das relações de exploração. Segundo Guillaumin (apud FALQUET, 2012, p.168-169):

[...] as relações de classe social, organizadas em torno da exploração, se situam em um plano material diferente das relações de sexo e de "raça", organizadas em torno da apropriação. A apropriação afeta a pessoa como um todo, corpo e "alma' sem medida, enquanto que a exploração afeta somente a força de trabalho, mensurada por peça ou em horas.

Guillaumin (2005) afirma que há dois tipos de apropriação: a individual ou privada e a coletiva. A apropriação individual é a realizada dentro da família, por meio do casamento. A coletiva, além de anterior, é mais profunda que a individual ou privada e é realizada, fundamentalmente, por meio das Igrejas, do Estado e das empresas. Como um exemplo da

\footnotetext{
${ }^{3}$ De acordo com Jules Falquet (2012, p. 140), com base no pensamento de Guillaumin, existem duas razões objetivas para se estabelecer um paralelo entre as relações (rapports) de "sexagem" com as de servidão e escravidão: "(1) o processo ideológico de naturalização das relações sociais [rapportssociaux], e (2) sua diferença comum com o assalariamento, ou se a gente preferir, com o modo de produção capitalista" (Destaque da autora; tradução nossa).
} 
apropriação coletiva, Guillaumin ainda cita as religiosas. E, como meios de obtenção das apropriações individual e coletiva, ela destaca: o mercado de trabalho; o confinamento no espaço; a demonstração de força; a coerção sexual; o arsenal jurídico e o direito consuetudinário.

Jules Falquet (2012) propõe acrescentar a esses meios: la contra inteprocréative ${ }^{4}$ [a coerção procriativa]. Além disso, a autora sugere:

(1) considerar o mercado de trabalho (seu primeiro meio) como resultante dos outros meios, (2) ter em mente os meios do sistema jurídico ou habitual, acrescentando as políticas públicas decorrentes das leis a que estão relacionadas, (3) renomear e conceituar mais amplamente os três outros meios (FALQUET, 2012, p.186, tradução nossa).

Para ampliar o entendimento desses meios de apropriação, Falquet (2012, p.211, grifo do autor, tradução nossa) propõe:

[...] transformar a ideia de confinamento no espaço, que pode facilmente ser lida como a ação de um marido restringindo sua esposa ao espaço doméstico, em restrição de mobilidade, que inclui mais ostensivamente as políticas migratórias restritivas em relação às mulheres ou a obrigação de fugir dos territórios em guerra sob a ameaça das agressões sexuais. Da mesma forma, a demonstração de força (as agressões) torna-se um continuum da violência masculina (violência e guerra) permitindo perceber melhor a forte dimensão de "gênero" das guerras, assim como os determinantes e consequências econômicas da violência doméstica ou sexual. Por fim, a coerção sexual torna-se - provisoriamente heterossexualidade como obrigação relacional para as mulheres.

No sistema capitalista, as relações de apropriação e exploração se combinam, até porque "a força de trabalho que se vende é indissociável do corpo que a porta, e as suas formas de apropriação e exploração estão definidas não só pelas relações de classe como também de 'raça' e de gênero" (ÁVILA, 2011, p.65). Com isso, por meio das apropriações advindas das relações de raça e sexo, o capitalismo as conduz para a sua dinâmica de exploração sobre a força de trabalho, ampliando o contingente humano disponível para os

\footnotetext{
4 "Eu entendo por isso o trabalho de ter uma gravidez em seguida de dar viabilidade a um bebê, na alimentação, cuidando e educando por um tempo frequentemente muito longo, muitas vezes, por várias décadas. Certamente, todas as mulheres não têm filhos, nem necessariamente muitos filhos. No entanto, quase todas as mulheres são vistas - e se veem - antes de mais nada como mães (reais ou em potencial)" (FALQUET, 2012, p. 177, tradução nossa).
} 
mais baixos salários e trabalho precários e, por conseguinte, aumenta sua capacidade de exploração associada a essas apropriações.

O racismo e o sexismo são fundamentais, portanto, para desvelar o sistema de exploração atual, mas não restritamente apenas do ponto de vista do trabalho. Como nos lembra Souza-Lobo (2011, p.288),

\footnotetext{
sexismo e racismo são questões políticas [diria também, econômicas], que fazem parte da nossa vida, do dia a dia das que procuram emprego, vão a hospitais ou postos de saúde, abortam escondidas como criminosas, amam, andam pelas ruas, cuidam dos filhos.
}

Isso significa que essas dimensões não são meras abstrações, mas são relações sociais que interferem concretamente na vida das mulheres e na negação de direitos a elas.

Nesse sentido, pensar em direitos humanos para as mulheres, exige lutar por uma sociedade sem patriarcado, racismo e classes sociais. Somente com a eliminação dessas determinações, as múltiplas violências contra a mulher podem ser radicalmente abolidas. Isso não significa que a luta contra a violência pode esperar por essa nova sociabilidade. Ao contrário, é no esteio da luta cotidiana contra a violência e por direitos humanos para as mulheres que se deve buscar construir novas relações sociais. Para tanto, creio que entender as múltiplas expressões e determinações dessa violência é indispensável para a compreensão da importância da luta por diretos humanos para as mulheres.

\section{Violência contra as mulheres e a violação dos direitos humanos}

A violência contra a mulher, face mais brutal e explícita do patriarcado, é entendida como toda e qualquer ação que fere a dignidade e a integridade física e/ou psicológica da mulher. Caracterizada por ter como o agente agressor direto o cônjuge ou ex-cônjuge, essa violência é determinada pelas relações desiguais entre homens e mulheres, mas, também, permeada pelas relações de classe e raça/etnia. Todas as mulheres, independente da classe e da raça/etnia em uma sociedade patriarcal estão sujeitas a sofrer violência, mas não indiferenciadamente. Ou melhor, a classe e a raça/etnia não apenas imprimem novas determinações de violência, mas, também, tornam as mulheres mais propícias a violências, além ainda de serem as mulheres pobres e negras as que mais têm dificuldades materiais para o enfrentamento dessas violências, posto que além de patriarcal, essa sociedade é racista e classista. 
Entre as múltiplas formas de violências contra a mulher, destaco:

1. Física: afeta diretamente o corpo da mulher por meio de agressões como empurrões, beliscões, bofetadas, pontapés, arremesso de objetos, queimaduras, feridas por arma branca ou de fogo, geralmente, deixando marcas, como hematomas, arranhões, feridas, cortes e cicatrizes.

2. Psicológica: ainda que não seja tangível, essa forma de violência deixa profundas marcas nas mulheres, que se manifestam no seu corpo e até mesmo no seu comportamento. Assim, ainda que não atinja diretamente ao corpo deixando marcas, ela acaba se manifestando nele por meio de expressões de tristeza, de pressão, expressões de medo e insegurança. Essa violência atinge diretamente a autoestima das mulheres e se materializa por meio de xingamentos, humilhações, cárcere privado, proibição de fazer amizades, privação econômica, entre outras (QUEIROZ, 2005). Essa violência está sempre presente nas demais formas de violência, pois todas elas afetam negativamente a autoestima da mulher.

3. Sexual: ocorre por meio do assédio sexual e quando uma mulher é forçada a fazer sexo contra a sua vontade, ou seja, por meio do estupro, seja ele praticado por um estranho, seja por seu cônjuge (nesse caso, denominado estupro conjugal). Aqui, a sexagem é explícita, ou seja, a coisificação da mulher como um objeto voltado para satisfação alheia, em detrimento de si própria e de seus desejos. Pesa nessa forma de violência a apropriação patriarcal mais latente sobre o corpo da mulher.

4. Patrimonial: ocorre quando objetos materiais e/ou de valor sentimental são destruídos pelo agressor, como uma forma de atingir a mulher.

5. Social: se expressa nas discriminações e preconceitos sofridos pelas mulheres nas relações sociais, a exemplo dos salários mais baixos em relação aos homens, da discriminação étnico-racial, da pequena representação feminina na política e nos espaços de poder. Além disso, a violência social se materializa na desqualificação e mercantilização das mulheres, muito comum nas propagandas e em letras de músicas.

6. Obstétrica: diferente das demais, essa forma de violência não necessariamente é praticada pelo cônjuge ou ex-cônjuge, embora também seja comum eles a praticarem, ao, por exemplo, obrigar uma mulher a abortar, ao xingarem uma 
mulher quando ela não consegue amamentar ou até mesmo por resumir a mulher a gestação e/ou à maternidade. Vinculada a uma perspectiva conservadora de maternidade, a violência obstétrica pode se manifestar na gestação, parto (inclusive, a proibição do direito a um(a) acompanhante no momento do parto), pós-parto, amamentação, exames de toque, esterilizações não consentidas, em situações de abortamento etc. Pesa nessa forma de violência, um forte moralismo sobre a mulher e uma cobrança social de um modelo de maternidade abnegada, na qual a mulher deve estar pronta para qualquer sacrifício, ainda que isso signifique passar por cima de suas necessidades.

Segundo o Dossiê: Violência Obstétrica "Parirás com dor", elaborado pela Rede Parto do Princípio para a CPMI da Violência Contra as Mulheres (REDE PARTO DO PRINCÍPIO, 2012), são comuns relatos de mulheres terem ouvido falar coisas, no momento do parto, do tipo: "Na hora que você estava fazendo, você não tava gritando desse jeito, né?"; "Não chora não, porque ano que vem você tá aqui de novo"; "Se você continuar com essa frescura, eu não vou te atender"; "Cala a boca! Fica quieta, senão vou te furar todinha"; “Na hora de fazer, você gostou, né?" (REDE PARTO DO PRINCÍPIO, 2012, p.2).

Ainda segundo o Dossiê (REDE PARTO DO PRINCÍPIO, 2012, p.2):

Essas frases são repetidamente relatadas por mulheres que deram à luz em várias cidades do Brasil e resumem um pouco da dor e da humilhação que sofreram na assistência ao parto. Outros relatos frequentemente incluem: comentários agressivos, xingamentos, ameaças, discriminação racial e socioeconômica, exames de toque abusivos, agressão física e tortura psicológica.

A violência obstétrica, quando expressa em situações de abortamento, ganha, muitas vezes, a sua forma mais cruel. Muitas mulheres não apenas são julgadas como passam por situações intensas de sofrimento, recebendo um tratamento agressivo, como uma espécie de "castigo"/penalização resultante de uma inquisição que, na verdade, nada mais é que negligência, o que contraria a Norma Técnica de Atenção Humanizada ao Abortamento do Ministério da Saúde (BRASIL, 2005) e o código de ética médica. Essa situação é o que propicia os altos índices de mortalidade materna relacionadas às complicações de situações de abortamento no Brasil. 


\section{A luta contra a violência às mulheres: alguns avanços legais e desafios no Brasil}

A despeito da sua gravidade e intensidade no país, a violência contra a mulher era tida como uma questão de ordem privada/pessoal até pouco tempo no Brasil. Foi apenas em 1980 que esse tema passa a ocupar a agenda dos direitos humanos, como resultado da luta das mulheres para que o Estado reconhecesse a violência como problema de ordem pública/política, e como tal reconhecesse a necessidade de órgãos especializados para o atendimento às mulheres vitimizadas.

O Brasil ratificou a Convenção sobre a Eliminação de todas as Formas de Discriminação contra a Mulher em 1984. Todavia, até 2003 o Brasil não havia apresentado o seu relatório sobre seus compromissos para acabar com a discriminação e a violência às mulheres. Nesse relatório, o Brasil, entre os países da América Latina, era o único que não possuía uma legislação específica sobre a violência contra as mulheres, bem como era incipiente no que diz respeito às parcas políticas públicas voltadas para a prevenção e combate à violência. Esse quadro, do ponto de vista normativo, muda apenas em 2006 com a Lei Maria da Penha (LMP) e recentemente, em 2015, com a Lei 13.104, que torna o feminicídio crime hediondo.

Os casos, geralmente, eram julgados pela Lei 9.099/95, que trata de "crimes de menor potencial ofensivo", sendo equiparados aos casos de briga entre vizinhos e de acidente de trânsito. Os homens agressores só eram presos em caso de homicídio ou lesão corporal grave, que impossibilitasse a vítima de trabalhar por mais de 30 dias. A LMP resultado de uma longa trajetória de luta dos movimentos feministas e dos direitos humanos, passando a reconhecer e tratar a violência contra a mulher como uma questão pública e, como tal, dever do Estado em intervir e coibir sua prática.

A concepção de violência contra a mulher por parte da LMP é ampla, incluindo a violência psicológica. Considero isso um grande avanço, posto que a violência contra a mulher, comumente, era restrita à violência física e, ainda assim, muitas vezes sendo encarada como um problema de ordem privada. Destaco, ainda, que a LMP foi a primeira lei brasileira a reconhecer a conjugalidade entre pessoas do mesmo sexo, abrindo, portanto, caminhos legais para a conquista de direitos por parte das pessoas não heterossexuais. 
A Lei, logo que sancionada, provocou grande resistência por parte do poder judiciário patriarcal, inclusive, acusando-a de inconstitucional o que, felizmente, não logrou êxito. Além disso, há a resistência passiva, ou seja, àquela traduzida em morosidade na implementação das varas especializadas, um mecanismo indispensável para efetivar os inquéritos e os processos. Isso demonstra como o direito patriarcal, "que institui o poder dos homens sobre as mulheres nas sociedades modernas ocidentais, viu-se fortemente ameaçado por esta lei" (ARTICULAÇÃO DE MULHERES BRASILEIRAS, 2011, p.48).

Dessa forma, incidir sobre uma forte estrutura burocrática, historicamente patriarcal, associada aos parcos recursos destinados às políticas de combate à violência contra a mulher, não é um contexto favorável à efetivação da LMP. A rede de serviços que a LMP prevê não é assegurada, sua efetivação ainda é bastante insuficiente e precária, concentrando-se mais nas capitais. A Articulação de Mulheres Brasileiras (2011, p.48) analisa e descreve, em síntese, um pouco dessa problemática em torno da efetividade da LMP:

\footnotetext{
Governos estaduais criam, mas não instalamos equipamentos (delegacias, casas abrigos, etc.). Outras vezes instalam em condições precárias sem pessoal ou sem infraestrutura física necessária, ou, como ocorre na maioria dos casos, tem debilidades de gestão da rede ou não investem recursos suficientes para a sua manutenção, funcionamento e ampliação. [...]

Um dos problemas identificados em nossas ações de monitoramento foram os entraves do sistema federativo, que obstaculiza muitos procedimentos de transferência de recursos. Outra questão é o despreparo dos recursos humanos e a prática de contratação por serviços temporários, levando a equipes provisórias nos serviços [...]. Se essa situação não invalida a política, positivamente avaliada, com certeza demonstra como o Estado patriarcal e sua máquina burocrática resistem a inovarem políticas que mudem a vida das mulheres.
}

Além da Lei Maria da Penha, também do ponto de vista normativo, ressalto como uma importante conquista a revisão e reedição da Norma Técnica sobre a Prevenção e Tratamento dos Agravos Resultantes da Violência Sexual contra Mulheres e Adolescentes. A norma data de 1998 e trata da regulamentação do artigo 128, inciso I do Código Penal, que possibilita o aborto legal às mulheres vítimas de estupro. A inovação da revisão consiste em não mais exigir o Boletim de Ocorrência para as vítimas de estupro realizarem o aborto legal. Além disso, passou a estabelecer regras e providências para assistência às mulheres vítimas de violência sexual. Com isso, conquistamos fomento para a implementação de serviços de saúde especializados para o atendimento a essas mulheres. Segundo a Articulação de Mulheres Brasileiras (2011, p.43), “de 2007 para 2010 o número 
de serviços que prestavam esse tipo de atendimento passou de 138 para 442 , sendo que desses 60 realizam atendimento para a realização do aborto previsto em lei".

Apesar de alguns avanços normativos, esses estão em constante ameaça, especialmente, os que dizem respeito ao aborto. No parlamento brasileiro, considerado o mais conservador desde a ditadura militar, estão em curso projetos de lei de cunho não apenas conservador, mas reacionário, posto que estão voltados não apenas para barrar avanços, mas, também, para retroceder em direitos. O Estatuto do Nascituro, voltado para a criminalização do aborto, revoga os casos de aborto legal no Brasil, "protegendo" o feto em detrimento da mulher, mesmo em caso de estupro ou risco de morte. O Estatuto da Família, por sua vez, define como família àquela constituída apenas por meio de um homem e uma mulher, com seus filhos(as), desconsiderando as famílias homoafetivas e, consequentemente, seus direitos.

Além disso, reforço a necessidade de investimento em políticas públicas (saúde, educação, trabalho, assistência social, previdência, habitação etc.) para as mulheres em uma perspectiva feminista, e a garantia da efetividade de uma rede de prevenção, proteção e combate à violência contra a mulher composta por Casas abrigo, Centros de Referência, Delegacias especializadas de atendimento à mulher e juizados especiais. Essa rede, no Brasil, está concentrada nas capitais e ainda assim de forma insuficiente. É preciso que essa rede atenda as mulheres do campo que sofrem ainda mais com as dificuldades para enfrentar a violência, uma vez que há um forte isolamento dessas no acesso aos equipamentos sociais e às políticas públicas.

Nesse sentido, os desafios mais imediatos para a garantia dos direitos humanos às mulheres, compreendem, fundamentalmente, a necessidade de uma contraofensiva à ideologia conservadora, hegemônica no parlamento brasileiro, e a luta por políticas públicas e equipamentos sociais. Esses são alguns dos desafios que os movimentos sociais e organizações de esquerda precisam enfrentar, sem, contudo, dissociá-los da necessidade de construção de um novo projeto societário.

\section{Conclusões}

As múltiplas formas de violência contra a mulher, seja ela física, seja psicológica, seja sexual, seja obstétrica, seja patrimonial, seja social, não resultam das relações individuais 
isoladamente, mas, sobretudo, são estruturadas pelas relações sociais de sexo, classe, raça/etnia, que consubstanciam a sociedade patriarcal-racista-capitalista. São essas relações que estruturam e dão base à ideologia patriarcal e racista que naturaliza situações de violências às mulheres.

É essa sociedade permeada por relações de opressão, exploração e também apropriação sobre as mulheres, que promove cotidianamente situações de violência permeadas e potencializadas pelo sexismo e pelo racismo, o que não apenas provoca a demanda pela luta por direitos humanos, mas a exige.

Falar em direitos humanos para as mulheres é, portanto, falar na necessidade de lutar por uma sociedade sem violência e sem as apropriações, explorações e opressões que dão corpo a essa violência. Para tanto, creio que o primeiro passo é desnaturalizarmos a ideologia patriarcal da subordinação e inferiorização feminina. A mulher precisa ser reconhecida e se reconhecer como sujeito de direito e não como uma "coisa" voltada para a satisfação e cuidado do outro. O segundo, é indispensável que a violência seja compreendida como um problema público/político e não de ordem individual/privado, exigindo intervenção do Estado por meio de políticas públicas e equipamentos sociais. Logo, a rede de proteção, assistência, combate e prevenção à violência, como prevista na Lei Maria da Penha, deve ser efetivada, não apenas nas grandes cidades, mas, também, no campo.

Entre as políticas públicas, além das voltadas para a segurança, saúde (física e psicológica) e acolhimento da mulher, gostaria de destacar a necessidade de se investir na política de educação. Acredito que uma educação não sexista e antirracista é fundamental para a formação de consciências livres de preconceitos e naturalizações de discriminações.

O terceiro passo, ao partir da compreensão de que o patriarcado afeta todas as relações sociais e impede a construção de uma sociedade democrática, penso que a luta contra ele e suas expressões não é uma responsabilidade apenas dos movimentos feministas. A luta antipatriarcal (dentro dela, a luta contra a violência às mulheres) deve ser incorporada na agenda de todas as organizações políticas de esquerda comprometidas com o avanço dos processos democráticos e com a construção de uma sociedade verdadeiramente igualitária, na qual as marcas da escravidão, do patriarcado e da exploração de classe nos sirva apenas de lembranças para que não se repitam. 


\section{Referências}

ARTICULAÇÃO DE MULHERES BRASILEIRAS-AMB. Políticas públicas para a igualdade: balanço de 2003 a 2010 e desafios do presente. Brasília: CFEMEA, 2011.

ÁVILA, M. B. As mulheres no mundo do trabalho e a relação corpo e sujeito. Cadernos de Crítica Feminista, Recife, ano 5, n. 4, dez. 2011.

BRASIL. Ministério da Saúde. Atenção humanizada ao abortamento: norma técnica. Brasília: Ministério da Saúde, 2005. Disponível em:

<http://bvsms.saude.gov.br/bvs/publicacoes/atencao_humanizada.pdf>. Acesso em: 27 set. 2015.

CISNE, M. Feminismo e consciência de classe no Brasil. São Paulo: Cortez, 2014.

FALQUET, J. Les mouvements sociaux dans la mondialisation néolibérale: imbrication des rapports sociaux et classe des femmes (Amérique latine -Caraïbes-France). Habilitation à diriger des recherches (mimeo). Paris: Université de Paris 8, 2012.

GOUGES, O. Declaração dos direitos da mulher e da cidadã. Interthesis, Florianópolis, v. 4, n.1, jan./jun. 2007. Disponível em:

$<$ https://periodicos.ufsc.br/index.php/interthesis/article/viewFile/911/10852>. Acesso em: 23 ago. 2015.

GUILLAUMIN, C. Práctica del poder e idea de Naturaleza. In: FALQUET, J.; CURIEL, O. (Org.). El patriarcado al desnudo: tres feministas maerialistas: Colette Guillaumin-Paola Tabet- Nicole Claude Mathieu. Buenos Aires: Brecha Lésbica, 2005.

MATHIEU, N. C. "¿ildentidad sexual/sexuada/de sexo? Tres modos de conceptualización de la relación entre sexo y género" In: FALQUET, J.; CURIEL, O. (Org.). El patriarcado al desnudo: tres feministas materialistas: Colette Guillaumin-Paola Tabet- Nicole Claude Mathieu. Buenos Aires: Brecha Lésbica, 2005.

NAÇÕES UNIDAS. Declaração universal dos direitos humanos: Brasília: UNESCO, 1998. Disponível em:

<http://unesdoc.unesco.org/images/0013/001394/139423por.pdf>.Acesso em: 20 maio 2015.

QUEIROZ, F. M. Não se rima amor e dor: representações sociais sobre violência conjugal. 2005. Tese (Doutorado em Serviço Social) - Universidade Federal de Pernambuco, Recife, 2005.

REDE PARTO DO PRINCÍPIO. Violência obstétrica: parirás com dor. Brasília, 2012.

Disponível em:

<http://www.senado.gov.br/comissoes/documentos/SSCEPI/DOC\%20VCM\%20367.pdf>. Acesso em: 24 set. 2015.

SANTOS, S. M. M. Direitos humanos, dominação ideológica e resistência. Revista Inscrita, Brasília, n. 12, p. 30-36, 2010. 
SOUZA-LOBO, E. A classe operária tem dois sexos: trabalho, dominação e resistência. São Paulo: Perseu Abramo, 2011.

Recebido em: $16 / 10 / 2015$

Aprovado em: 26/11/2015 